\title{
GEOGRAPHICAL INFORMATION SYSTEM \\ FOR THE CULTURAL HERITAGE AND PROTECTED LANDSCAPE OF REGIONE TOSCANA
}

\author{
R. Costantini a, *, L. Angeli a, R. Ferrari a, L. Innocenti a, M. Del Buono b \\ a Consorzio LaMMA, via Madonna del Piano 10, 50019 Sesto Fiorentino (FI), Italy - \\ (costantini, angeli, ferrari, innocenti)@lamma.rete.toscana.it \\ b Ministero per i Beni e le Attività Culturali - Direzione Regionale per i Beni Culturali e Paesaggistici della Toscana, \\ Lungarno Anna Maria Luisa de’ Medici 4, 50122 Firenze, Italy - marinella.delbuono@beniculturali.it
}

KEY WORDS: Cultural Heritage, Conservation Measures, Geographical Information System, Cartography, Regione Toscana, Ministero per i Beni e le Attività Culturali

\begin{abstract}
:
LaMMA Consortium, with collaboration of Regione Toscana and Ministero per i Beni e le Attività Culturali (MiBAC), has created the web Geographical Information System for Cultural Heritage and Protected Landscape of Regione Toscana. This system now makes it possible to access the digital maps and the digital archives of archaeological, architectural and landscape related restrictions over the entire region. In order to continuously update the realized system for maintaining its utility and validity, Regione Toscana together with MiBAC signed a protocol agreement (2004), according to which every new restriction measure issued is sent as a copy also to the regional offices and then to LaMMA Consortium, that attends to update the digital archives and the digital maps. Thanks to this agreement, the system counts today over 18,000 measures, with an average yearly increase of almost 250 measures, that determine restrictions for 9.000 areas.
\end{abstract}

\section{INTRODUCTION}

In the period 1999-2001 Regione Toscana, in cooperation with the Laboratory for Meteorology and Environmental Modelling (now LaMMA Consortium), took part, together with other Italian regions and the Istituto Centrale per il Restauro (ICR) branch of the Ministero per i Beni e le Attività Culturali (MiBAC), in the European Project INTERREG IIC Medoc named Risk Map (Costantini, 2001a; Costantini, 2001b).

The experience gained, thanks to the project, drew attention to the fact that the archives of the several Soprintendenze* are not easily and quickly accessible and it is not always possible to exactly locate the assets because of the enormous quantity of documentation produced in more than one century of activity (the oldest protection act refers to law number 364 in 1909), and because of the cadastral and toponymy changes that took place in this period (Costantini, 2001c).

In this context a follow-up regional project Carta dei Vincoli was realized (2001-2003), evolved into the Geographical Information System for Cultural Heritage and Protected Landscape of Regione Toscana. This system gives today the possibility to access the digital maps and the digital archives of archaeological, architectural and landscape related restrictions over the entire region.

In agreement with MiBAC, in order to obtain a homogenous product able to give unambiguous information ${ }^{* *}$, the survey was

* Peripheral organs of the Ministero per i Beni e le Attività Culturali (Ministry of Culture) with the institutional task of protecting, conserving and valorising the architectural and landscape heritage in the territory of competence.

* ${ }^{*}$ Considering the outstanding amount of data (up today more than 17.000 measures acquired, with more than 85.000 scanned pages) and the historical layering of information. focused on Cultural Heritage with explicit conservation measures, postponing the examination of all other assets filed or registered, in the second instance. This made it possible to create a tool directly usable by the local administrators, to access and locate all measures with legal effectiveness that are subject to specific governmental discipline.

\subsection{Short Historical Excursus on the Conservation Cultural Heritage Normative in Italy}

In Italy during the Risorgimento, almost all states had issued more or less homogenous laws for the conservation of the antiquities, works of art and archaeological areas.

The State of the Church was the one that could boast the oldest tradition concerning laws, for example it had edicts for police control on conservation and trade of antiquities and works of art with the purpose of preventing masterpieces destruction and dispersion. In the broad group of laws of the Papal State it must be highlighted a particular measure issued by Cardinal Pacca in 1820 , under Pio VII Pope. This was the first homogenous measure to protect the cultural and historical heritage and was the inspiration for similar measures in Naples Kingdom, in Tuscany and in the Kingdom of Lombardy-Venetia.

In contrast in Piemonte there were not important normative interventions, with the unique exception of the Giunta di Antichità e Belle Arti founded in 1832 for proposing conservation measures for antiques and works of art.

Almost everywhere in Italy there was a consciousness raising about the artistic and historic heritage but, with the exception of the State of the Church and Kingdom of Naples, the other states limited their laws in order to avoid the works of art escaping from the state.

After Italian unification, the Kingdom of Italy completely disregarded cultural heritage. With the Statuto Albertino, that 
ratified properties sanctity, state meddling on this topic was not allowed at all. This was the reason of private initiatives origin. The only exception in this picture is represented by law number 2359 in 1865 about the possibility to expropriate monuments ruined by the owner's negligence.

The first set of laws (number 185 in 1902 and number 364 in 1909) concerning the principle of public significance and the preservation obligation of cultural heritage together with the acknowledgement of the public administration action power, goes back to the beginning of the XX century, when for the first time the public nature of works of art was stated and the necessity of safeguard was recognized.

The first important attempt to give an homogenous and systematic structure to the set of laws concerning the Italian cultural heritage was made through the foundation of a unique Consiglio dell'Educazione, della Scienza e delle Arti only in 1939, with the laws number 1089 and number 1497.

These rules were aimed not only to protect but also to enhance the cultural heritage and related activities, especially through the use of grants and subsidized credit. Anyhow these measures, intended to ensure the fruition and appreciation of those assets, remained in the background compared to those, still predominant, direct to ensure the conservation, protection and enforcement of circulation restrictions.

Only with the Constitution of the Italian Republic, the Italian State action directed to protect and promote the culture, becomes a fundamental principle of the Republic: article 9 does not only to take into account the preservation of cultural heritage, but ratifies the cultural function of the State in the preservation of interests relating to cultural properties.

But the term cultural heritage goes into the Italian system only in more recent times, following the ratification of international conventions after World War II: the term makes its first appearance only in The Hague Convention in 1954. Ten years later, Commissione Franceschini gives an important contribution to the definition of cultural heritage, intending by this term "all assets [...] for the collective fruition - regardless of public or private property - as concrete evidence having culture value".

However, an important innovation in recent legislation is marked by the passage from a legislation substantially made by restriction measures (in 1939), to a dynamic role of cultural policy, which aims to ensure the widest availability of the cultural heritage value. For the first time the State is obliged to bears the costs of restoration if the owner of the asset is not in the position to support them (law number 1552 in 1961); the 1970 Presidential Decree number 805 used the term enhancement for the cultural heritage; in 1982 law number 512 funds allocates and cash donations for the promotion of cultural events, together with interventions to improve safety conditions of museums and cultural institutions; private citizens can be directly involved in the management of ancillary services with fee in museums, galleries, libraries (law number 4 in 1993).

Afterward, the legislature introduced a new important measure with the Consolidated Law concerning cultural and environmental heritage (Legislative Decree number 490 in 1999). The Decree lets the local administration have a broader management role and expands the protection area to photographs, to music papers, films and audiovisual works and other assets which, although not listed, constitute evidence of cultural value.

The new Cultural Heritage and Landscape Code (number 42 in 2004) replaces the above mentioned Consolidated Law. With this Code important innovations are introduced from a revision point of view of cultural heritage legislation in order to organically and systematically regulate the cultural, historical and artistic Italian heritage. An important aspect is the distinction between protection and enhancement, assigning the first to the exclusive state legislation and the second to the regions legislation. In addition the enhancement, that is also considered as a social benefit, is distinguished as deriving from public or private initiatives.

Another significant change concerns the Landscape whose protection and enhancement is assigned to the Ministry in concert with the regions. The Code assigns to the regions the landscape planning task (Costantini et alii, 2004).

\section{THE ARCHIVE CREATION}

In 2001, with the European project ending, Regione Toscana decided, with the collaboration of the Direzione Regionale per $\mathrm{i}$ Beni Culturali e Paesaggistici della Toscana (as a department of MiBAC), to fund the "Carta dei Vincoli" project, commissioning LaMMA to realize the first and as exhaustive as possible, Cultural Heritage Census, that consists, as showed in Figure 1, of:

$\rightarrow$ a database of all assets and all measures for archaeological, architectural and landscape related restrictions;

$\longrightarrow$ a digital cartography of all constraint areas;

$\longrightarrow$ a catalogue of all scanned documented constraints existing in the Soprintendenze archives.

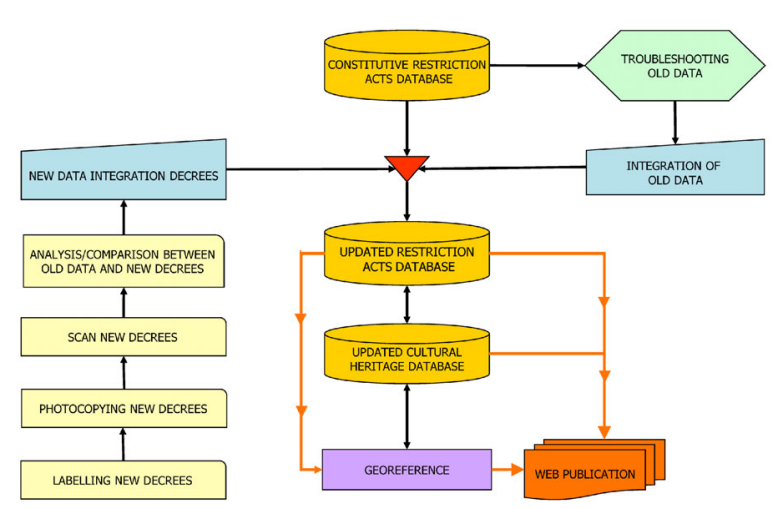

Figure 1: Workflow for realization of the Cultural Heritage Information System.

This first phase, ending in December 2003, let us know the exact amount of the Cultural Heritage in Tuscany: 7,000 archaeological, architectural and landscape areas with more than 15,000 restriction measurements.

Technically the following actions have been taken (Costantini et al, 2005):

1. Documents investigation and selection from the Soprintendenze.

2. Acquisition, through photocopying, of the whole paper documentation, including plans, historical and artistic reports, kept in the offices of the Soprintendenze.

3. Scanning of all acquired documentation, with the realization of an indexed catalogue, that contains about 60,000 images.

4. Creation of an alphanumeric database (Cultural Heritage archive), containing all identifying information of the assets subject to the restriction measure (name, 
address, cadastral reference, type of restriction measure, etc.).

5. Creation of an alphanumeric database (Restriction acts archive), containing indication on all restriction measures for each single area.

6. Realization of digital cartography of areas subject to the restriction measure, congruent with the Regional Technical Map (scale 1:2,000 or 1:10,000).

7. Realization of a Web Portal to access the archives.

8. Creation of an Internet Map Server, integrated with the Web Portal, for Cultural Heritage location on the digital cartography.

\section{ARCHIVES ONGOING UPDATING}

In order to continuously update the realized system for maintaining its utility and validity (Figure 1), Regione Toscana together with Direzione Regionale per i Beni Culturali e Paesaggistici (MiBAC), signed a protocol agreement (April 2004), according to which every new restriction measure issued is sent as a copy also to the regional offices and then to LaMMA Consortium, that attends to update the digital archives and the digital maps (Costantini et alii, 2007; Costantini, 2009). Thanks to this agreement, since 2004, LaMMA Consortium update the whole Information System monthly.

As a result of the ongoing updating, up to today (December 2011) the system counts over 18,000 measures, with an average yearly increase of almost 250 measures, that determine restrictions for over 9,000 areas (archaeological, architectural and landscape).

\section{THE WEB PORTAL}

Through the Web Portal of the Geographical Information System for the Cultural Heritage and Protected Landscape of Regione Toscana (reachable from Regione Toscana homepage www.regione.toscana.it or from LaMMA homepage www.lamma.rete.toscana.it), it is possible to consult both the GIS cartography (Figure 2) and the digital archives of Cultural Heritage with restriction measures (Costantini et al, 2007).

The scanned documentation related to restriction decrees is accessible only to the Ministry personnel subject to specific access credentials (Costantini et al 2007; Costantini, 2009).

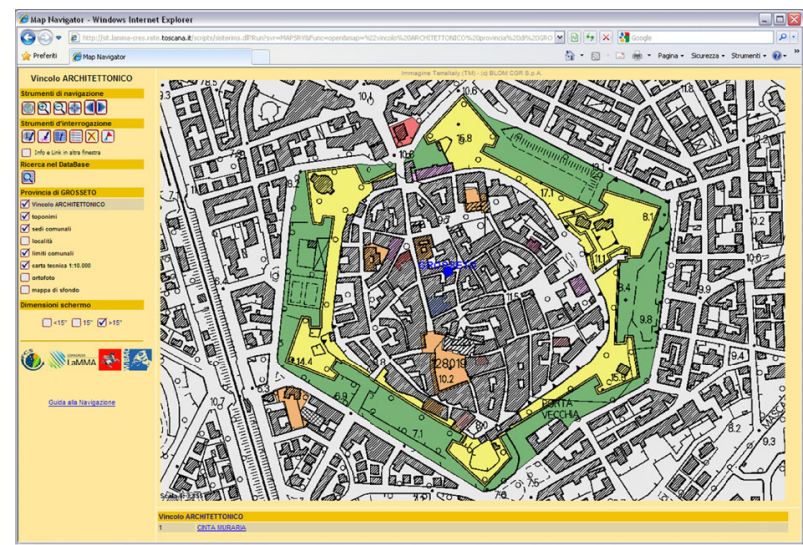

Figure 2: Example of the GIS cartography through the Web Portal

\subsection{Restriction Acts Database}

According with MiBAC, a specific table has been designed having each record linked to an unambiguous restriction measure (decree, declaration, recognition letter, alienation authorization) (Costantini et alii, 2005).

The fields of the table are:

- Unambiguous ID code that identify univocally the single decree

$\rightarrow$ Unambiguous ID code that identify the Cultural Heritage subjected to the restriction measure

$\rightarrow$ Name of the Cultural Heritage like is written on the restriction measure text

$\rightarrow$ Province where the Cultural Heritage is located

$\rightarrow$ Municipality where the Cultural Heritage is located

- Address of the Cultural Heritage like is written on the restriction measure text

$\rightarrow$ Date of the issue of the decree

- Note: particularity that might exist in the restriction measure text

\subsection{Cultural Heritage Database}

Since an area can have several restriction measures, the relation between Cultural Heritage table and Restriction acts table is one to many.

The Cultural Heritage table in the database is more complex than the decrees one (Costantini et al, 2005). As a matter of fact the area identification data can derive even from many different restriction measures. It is the case where the Cultural Heritage name has changed in time (i.e. Palazzo Gualfonda ex Giuntini), or where the property is constituted by several cadastral parcels with different owners.

The fields of the Cultural Heritage table are:

- Unambiguous ID code that identify univocally the single area

$\rightarrow \quad$ Name of the Cultural Heritage like is written on the restriction measure text

- Category: it refers to the architectural type (i.e. abbey, fortification, etc...)

- Respect Zone: Direct or Indirect conservation measure enforce to the area

$\rightarrow$ Province where the Cultural Heritage is located

$\rightarrow$ Municipality where the Cultural Heritage is located

- Address of the Cultural Heritage on the current toponymy

$\rightarrow$ Cadastral References: group of cadastral parcels of the restricted area

$\rightarrow$ Reference Regulations of the first restriction measure issued: law of the first restriction measure for that specific area

- Date of the issue of the first restriction measure: date on the first restriction measure issued

- Reference Regulations of the latest restriction measure issued: law of the latest restriction measure for that specific area

- Date of the issue of the latest restriction measure: date on the latest restriction measure issued

$\rightarrow$ Note: particularity that might originate from the whole of the restriction measures

\subsection{Cartography}

In order to represent the real areas subject to the restricted measures, a polygonal cartography for the Cultural Heritage was created (Monti et al., 2004). 
The geographic area boundaries maintained in the Cultural Heritage Geographical Database respect the limits of the entities that they represent (e.g., buildings, historical gardens, churches) or on which they are based (e.g., cadastral parcel of land).

Since the input data used to create the Geographical Database was obtained from several sources having a diverse range of scales (Cadastral Map -1:4,000), CTR - 1:2,000, 1:10,000, IGM $-1: 25,000)$, the accuracy* ${ }^{*}$ of the polygons boundary is based on the accuracy of the source material used in its production. In detail:

- The areas subject to archaeological constraint have been delineated on the base of the cadastral map since the perimeter often does not have a corresponding topographic element on the Regional Technical Map: in extra urban areas without constructions, the cadastral parcels boundary lines were taken as reference.

$\rightarrow$ The areas subject to architectonic constraint have been delineated on the base of the Regional Technical Map (in urban areas with 1:2.000 scale, in extra urban areas with 1:10.000 scale), through an interpretation/conversion work of the boundary elements; thereby the resulting cartography is a technical map directly usable for municipality and urban planning.

$\rightarrow$ Finally, the areas subject to landscape constraint, although they are originally delimitated with elements of the cartography with a scale 1:25.000, have been delineated on the base of the Regional Technical Map with 1:10.000 scale (Angeli et alii, 2010), through a careful interpretation/conversion work of the boundary elements, that allowed an up-scaling operation.

The resulting cartography is a technical map that is transmitted to the municipalities of the Regione Toscana. They can directly use it in their Geographical Information Systems for landscape planning and environmental management, overlapping the implemented thematic map with other geographical layers concerning environmental risks like landslides, flood areas, etc. (Angeli et alii, 2007).

\subsection{Digital Catalogue of Restricted Measures}

The Digital Catalogue of restricted measures includes the whole constraint documentation for each Cultural Heritage (decrees, plans, historical and artistic reports, etc.).

Each paper document, obtained through photocopying the original stored by the Soprintendenze, was indexed with an unambiguous numeric code and scanned.

\section{RESULTS}

All the ten provinces of Tuscany and their municipalities, utilize the products implemented with the GIS for Cultural Heritage and Protected Landscape of Regione Toscana for the execution of their landscape planning activities. This implies a common interest in maintaining the system running and always updated, with the notification of possible inexactness.

\section{CONCLUDING REMARKS}

The GIS for Cultural Heritage and Protected Landscape of Regione Toscana is constantly utilized by several local governments in charge for land planning (MiBAC, Regione Toscana, municipalities). Additionally also professional categories like architects, engineers and building surveyors, uses the realized system to facilitate the information gathering for their planning activities.

During 2012 the web accesses to the system reached and surpassed the quote of 20.000 .

\subsection{Future Improvements}

In consequence of the aroused interest in the system, a WMS (Web Map Service) is under implementation.

Moreover, in order to provide facilitate access to the GIS for Cultural Heritage and Protected Landscape of Regione Toscana and to share knowledge, would be very stimulating to be part of a cross-domain portal like Europeana. By the end of 2012, after receiving the MiBAC certification, a partnership between the Cultural Heritage Department of Regione Toscana and Europeana is expected.

\section{References from Proceedings and Books:}

Angeli, L. (et al.), 2010. Carta dei Vincoli Paesaggistici della Regione Toscana. VI Conferenza Nazionale Informatica e pianificazione urbana e territoriale. Potenza 2010 Proceeding, ISBN: 9788896067451, Vol. I, pag. 199-209

Angeli, L. (et al.), 2007. Il Sistema Informativo Territoriale delle aree soggette a vincolo Paesaggistico della Regione Toscana. XI Conferenza nazionale ASITA. Torino 2007 Proceeding, ISBN: 978-88-903132, Vol. I, pp. 803-808

Costantini, R., 2001b. Sistema geografico di integrazione degli archivi dei beni culturali e ambientali della Toscana. XII edizione del FORUM della Pubblica Amministrazione, Roma 2001 Oral Communication

Costantini, R., 2009. Il Sistema Informativo Territoriale per i Beni Culturali e Paesaggistici della Regione Toscana. Brochure Dire \& Fare: XII rassegna dell'innovazione nella Pubblica Amministrazione, Firenze (Italy). Oral Communication

Costantini, R. (et al.), 2005. Strumenti per la tutela, la valorizzazione e la gestione del patrimonio culturale. IX Conferenza nazionale ASITA. Catania 2005 Proceeding, ISBN: 88-900943-9-7, Vol. I, pp. 53-58

Costantini, R. (et al.), 2007. Strumenti e metodi per la tutela, la valorizzazione e la gestione del patrimonio culturale: verso il Sistema Informativo Territoriale per $i$ Beni Culturali della Regione Toscana. XVIII edizione del FORUM della Pubblica Amministrazione, Roma (2007) Oral Comunication

Costantini, R. (et al.), 2004. Carta dei vincoli: la condivisione della conoscenza, Firenze (2004) Regione Toscana (Ed.)

Monti, C., (et al.), 2004. La carta del rischio del patrimonio culturale in Lombardia - Guida per la georeferenziazione dei beni storico-architettonici. ISBN: 88-8335-506-7

\footnotetext{
Accuracy: how closely the data represent the real world
} 


\section{References from Other Literature:}

Costantini, R., 2001a. Relazione sintetica finale Progetto Carta del Rischio del Patrimonio Culturale. Programma comunitario INTERREG IIC Mediterraneo Occidentale e Alpi Latine. Report, Firenze (Italy).

Costantini, R., 2001c. Rapporto finale ufficiale sulle attività di schedatura e studio di fattibilità per la georeferenziazione dei beni architettonici nell'ambito del progetto "Carta dei beni culturali della Regione Toscana", complementare al progetto "Carta del rischio del patrimonio culturale". Programma comunitario INTERREG IIC Mediterraneo Occidentale e Alpi Latine. Report, Firenze (Italy) 
